\title{
EQUiLIBRIUM
}

Quarterly Journal of Economics and Economic Policy

2015 VOLUME 10 ISSUE 3, September

p-ISSN 1689-765X, e-ISSN 2353-3293

www.economic-policy.pl

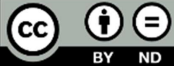

Reklaitè, A. (2015). Globalisation Effect Measure Via Hierarchical Dynamic Factor Modelling. Equilibrium. Quarterly Journal of Economics and Economic Policy, 10(3), pp. 139-149, DOI: http://dx.doi.org/10.12775/ EQUIL.2015.029

Agnẻ Reklaitė*

Vilnius University, Lithuania

\section{Globalisation Effect Measure Via Hierarchical Dynamic Factor Modelling}

JEL Classification: $C 43 ; E 32 ; C 10$

Keywords: leading indicator; hierarchical dynamic factor model; globalisation; economic growth

\begin{abstract}
In this paper the issue of globalisation and deteriorating precision of domestically oriented frameworks is addressed. A hypothesis that the effect of international trends on the growth of economy is increasing over time is formed. In order to validate this, a method of composing foreign series with local indicators in a hierarchical dynamic factor model is presented. The novelty of this approach is that globalisation effect is measured focusing on prediction rather than similarity. This way the measure presents the country's sensitivity to global shocks and reveals how much focal country's economy is intertwined with global economy. The application was performed on the basis of Lithuanian data and the hypothesis was validated. The results indicate that globalisation effect has an increasing effect over time.
\end{abstract}

(C) Copyright Institute of Economic Research \& Polish Economic Society Branch in Toruń Date of submission: March 24, 2015; date of acceptance: June 1, 2015

* Contact: agne.reklaite@mif.vu.lt, Department of Econometric Analysis, Vilnius University, Naugarduko st. 24, LT-03225 Vilnius, Lithuania 


\section{Introduction}

The globalisation is increasingly addressed as the underlying cause of diminishing accuracy of traditional domestically oriented macro-econometric models. An example of extended Conference Board methods (Drechsel \& Sheufele, 2010) shows that more and more indicators have to be incorporated into leading index construction to keep up with the accuracy of previously constructed models. This result could indicate that processes are becoming of more complicated structure, impelled by increasing amount of information available for a single agent of economy and therefore affecting its decision-making. The accuracy of domestically oriented models deteriorates with time and this phenomenon is addressed by Fichtner et al. (2009). They find that it is caused by globalisation, however adding information about external environment improves the forecast performance.

Globalisation measure has been constructed by other authors although with different focus. Deher et al. (2008, pp. 25-74) label globalisation as multi-domain, pluralistic phenomenon which consists of many processes, so they take a complex approach to construct index based on many indicators which reveal globalisation presence. Kearney (2004) globalisation index is a cannonical exaple of such measure. It is an aggregate weighted index calculated from incidators of areas: political engagement, technology, personal contact and economic integration. This index is quantitative, but relies heavily on weighing and this weakness is often addressed by other authors, e.g. Lockwood (2004, pp. 507-623), Heshmati (2006). This index is also critisised for not being clear of what exactly it measures and that indicators from different countries are calculated using different methodologies, therefore not posessing the desired feature of cross-comparablility (Castelli, 2008, pp. 383-404).

Another approach to measure globalisation in based on international trade; e.g. Naghshpour and Sergi (2009, pp. 1-24) created an index by classifying and ranking the countries on their imports and exports or international trade share to GDP. This method is useful for comparing countries, but does not contribute to the dynamic aspect and does not address globalisation in the time domain. Another example of using international trade to inspect and measure the globalisation is study by Kim and Shin (2002, pp. 445-468). Their method was network based and revealed interesting patterns in geographical domain. They also compared 2 time periods (1959 and 1996) and made generalisations about globalisation process from them: the international trade is becoming denser due to globalisation. 
The similarity in dynamics of economic indicators in different countries could be measured in various ways, but the most popular method is some sort of factor modelling. The findings of Cubadda et al. (2012) show that a a common factor explains a lot of co-movements of different European countries therefore including data of other countries could help acquire better accuracy in evaluating models, since the factor model approach is data greedy. Andersen and Herbertsson (2003, 2005, pp. 1089-1098) analysed indicators of economic integration, applied factor analysis to measure the commonality across different countries and calculated the index of globalisation. Similar results were aquired by Maslov (2001, pp. 397-406) using the similar methods (principal component analysis) on financial time series.

The findings of mentioned authors suggest that the component of foreign information in economic models is gaining more importance. Statistical explanation for this could be that the foreign component of these processes was always present, but was discarded as insignificant, because of its noise-like features. However, due to globalisation indicators from different economies are becoming more similar and supranational element is becoming more apparent. This effect should be particularly visible for small open economies.

In the light of these statistical observations it was decided to take a new approach on measuring the globalisation effect with the focus on prediction. Other authors like Andersen and Herbertsson (2003) measure the similarity of economic indicators across different countries. However this way the 'globalisation effect' might be represented by spurious relationships. Therefore prediction based measurement could indicate country's sensitivity to global shocks and reveal how much focal country's economy is intertwined with global economy. This way we could define what we want to measure: the globalisation impact as a proportion of economy growth explained by supra-national factors.

The relationship between globalisation and the growth of economy has been analysed by many authors, e.g. Dreher (2006, pp. 1091-1110) found that globalisation promoted economic growth, Quinn's and Toyoda's (2008, pp. 1403-1449) findings reveal that liberalization of capital account had a positive association with growth in both developed and emerging market nations, Villaverde and Maza (2011, pp. 952-971) conclude that globalisation has been one of the main drivers of economic growth. Those authors mostly distinguished the relationship between the degree of globalisation measured by Kearney or similar indexes and the growth rates of economy. The novelty of this paper is that it tries to reveal what part of the economic growth was generated from drivers of globalised economic envi- 
ronment and measure this effect in the time domain so that the monitoring of the globalisation impact could be performed. Another issue that is addressed in this paper is the dynamics of measured globalisation effect: does it grow in magnitude?

The main hypothesis in this study is: the effect of international trends on the growth of economy increases over time. In order to distinguish and quantify domestic and foreign factors, the structural approach is required and a dynamic hierarchical factor model was built following Moench et al. (2009).

The main objectives of this paper are the following:

- to adapt the hierarchical dynamic factor model to distinguish and evaluate the effect of domestic and foreign drivers of the economy and attain a quantitative measure of magnitude of either effect in the time domain

- to apply the new method for Lithuanian data

- to validate the hypothesis that due to globalisation the proportion of economic growth forecast explained by foreign indicators is increasing over time

\section{Methodology of the Research}

Since the main objectives are to determine the load of domestic and foreign drivers on the growth of focal economy, the leading indicators approach is used. The GDP growth was used as a measure for economy growth. The leading series are indicators which have information about future growth of economy. Therefore they are identified and selected for modelling if serial cross-correlation and Granger causality test reveals it. The selected series are used in the following steps of study after necessary transformations (stationarisation and scaling).

The structural methods are necessary in order to distinguish domestic and foreign components of economy drivers. For this reason, it was nessesary to enforce structural division of domestic and supra-national indicators, and the hierarchical dynamic factor model served that purpose very well. The time series were organised into 2 blocks: one for the domestic and the other for the foreign indicators in order to capture the information and its apportionment from different domains. This specification allows us to evaluate separate latent factors for domestic and foreign blocks and later use them to evaluate each of their load on the future growth of economy. The evaluation of this model was performed using Monte Carlo Markov Chain (MCMC) simulations with Gibbs sampling technique assuming gaussian inovations. 
After the evaluation of domestic and foreign factors, the weights of each of the factor were quantified using two different models. First, a regression was built with future GDP growth as dependent variable and domestic and foreign factors as regressors. This regression gave time-invariant coefficients, which revealed average infuence of domestic and foreign factors on economy growth over time. Afterwards another approach was used in order to evaluate time-varying coefficients. A dynamic linear model was built to identify time-varying weights of domestic and foreign factors on the growth of GDP. The initial values were selected calculated using the results from regression of GDP growth on evaluated factors.

\section{The Leading Indicators}

Since the global economic environment is described by many indicators, the Stock and Watson (2002) method for macroeconomic forecasting using diffusion indexes was chosen. This method allows to use many predictors which could be cumbersome for some traditional techniques such was vector auto-regression or structural equation modelling. The factor model also deals with an issue of indicators being not suitable for cross-comparibility (due to different methodologies of measurement in different countries) addressed by Castelli (2008, pp. 383-404). Factor model lets us extract signal from large panel of data series, therefore discrepancies caused by different measurement methods are discarded as noise.

The selection of leading indicators was performed following Gaudreault et al. (2003). An initial data set consisted of almost all Lithuanian quarterly economic indicators starting at least at 1998 (this date was important since there was a recession in 1998-1999 and it would be interesing to monitor the results in this particular period), and the major economic indicators of Lithuania's top 20 international trade partners. Leading series were selected based of three criteria:

1. Granger causality

2. Correlation between series $\Delta X_{i,(t-l)}$ and GDP growth $\Delta G D P_{t}$ should be greater with lags $l>0$

3. $R^{2}$ criterion should be bigger in regression $\Delta G D P_{t}=\Delta X_{i, t-l}+e_{t}$ with lags $l>0$

Only the series that met all three criteria were selected. A three-level model was built, and separate factors were estimated for domestic and foreign variables, since the domestic series were organised into one block, while another block contained the foreign series. The domestic block consisted of 4 time series and foreign block was formed from 20 series. The 


\section{Agnè Reklaité}

domestic leading indicators largely overlaped with selected leading indicators from another study where they were used for constructing Lithuanian leading economic index (Reklaite, 2011, pp. 91-107).

\section{The Hierarchical Factor Model}

The equations constituting the three level hierarchical model are the following:

$$
\begin{gathered}
X_{b i t}=\Lambda_{G, b i} G_{b t}+e_{X b i t} \\
G_{b t}=\Lambda_{F, b} F_{t}+e_{G b t} \\
\psi_{F}(L) F_{t}=\varepsilon_{F t}
\end{gathered}
$$

$X_{\text {bit }}$ are leading series, which were transformed to be stationary and scaled, index $b$ denotes the block (either domestic or foreign), $i$ denotes index of time series, $t$ denotes time index. $\Lambda_{G}$ and $\Lambda_{F}$ are loadings, $G_{b t}$ are blocklevel factors, $F_{t}$ is a common factor. The equation (3) describes stationary AR(1) process. $e_{X b i t}, e_{G b t}$ and $\varepsilon_{F t}$ have zero mean and their variances $\Sigma_{X}=\operatorname{cov}\left(e_{X b i t}\right)$ and $\Sigma_{G}=\operatorname{cov}\left(e_{G b t}\right)$ are assumed to be diagonal. The evaluation of this model was carried out following the procedure by Moench et al. (2009), via Markov Chain Monte Carlo (MCMC) using Gibbs sampling technique (Carter \& Kohn, 2004, pp. 541-553), under assumption of Gaussian innovations. Data series are structured into 2 blocks $b=1,2$. Each series $i$ in a given block $b$ is decomposed into a serially correlated idiosyncratic component $e_{X b i t}$ and a common component $\Lambda_{G . b i}(L) G_{b t}$ which it shares with other variables in the same block. Each block level factor $G_{b j t}$ has a serially correlated block-specific component $e_{G b j t}$ and a common component $\Lambda_{F . b j}(L) F_{t}$ which it shares with all other blocks. Finally, the economy-wide factor $F_{t}$ is assumed to be serially correlated. In this model, variables within a block can be correlated through $F_{t}$ and the $e_{G b j t}$ 's, but variables between blocks can be correlated only through $F_{t}$. Estimation procedure by MCMC: Let $\boldsymbol{\Lambda}=\left(\Lambda_{G}, \Lambda_{F}\right), \boldsymbol{\Psi}=\left(\Psi_{F}, \Psi_{G}, \Psi_{X}\right)$, $\boldsymbol{\Sigma}=\left(\Sigma_{F}, \Sigma_{G}, \Sigma_{X}\right)$.

1. Organize data into blocks to yield $X_{b t}, b=1, \ldots, B$. Use principal components to initialize $\left\{G_{t}\right\}$ and $\left\{F_{t}\right\}$. Use these to produce initial values for $\boldsymbol{\Lambda}, \boldsymbol{\Psi}$ and $\boldsymbol{\Sigma}$. 
2. Conditional on $\boldsymbol{\Lambda}, \boldsymbol{\Psi}, \boldsymbol{\Sigma}$ and $\left\{F_{t}\right\}$ draw $\left\{G_{t}\right\}$ taking into account time varying intercepts.

3. Conditional on $\boldsymbol{\Lambda}, \boldsymbol{\Psi}, \boldsymbol{\Sigma}$ and $\left\{G_{t}\right\}$ draw $\left\{F_{t}\right\}$.

4. Conditional on $\left\{G_{t}\right\}$ and $\left\{F_{t}\right\}$, draw $\boldsymbol{\Lambda}, \boldsymbol{\Psi}$ and $\boldsymbol{\Sigma}$

5. Return to 2.

One dynamic factor for each block and one common factor were evaluated. 10000 iterations were made, and first 500 were dropped out as a "burn-in". The domestic and foreign leading factors were evaluated calculating the expectation from posterior distributions. The estimations were carried out using $d l m$ package (Petris, 2010) of statistical software $R$. The resulting factors are plotted in Figure 1.

Figure 1. Evaluated common, domestic and foreign leading factors from the hierarchical factor model

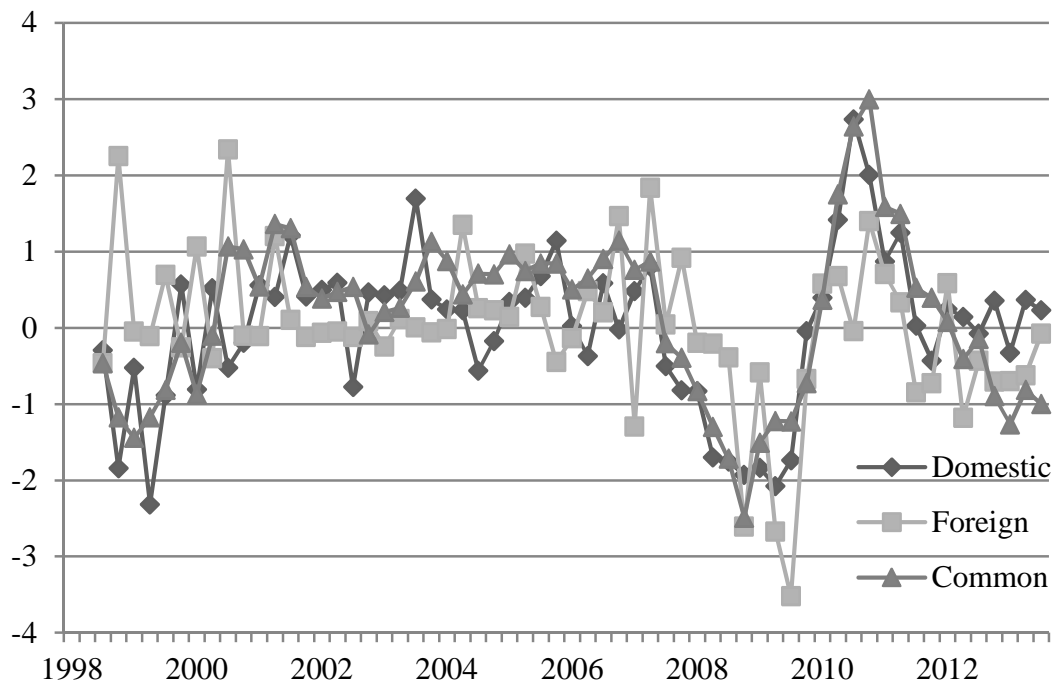

Source: author's calculations.

The results indicate that even though the extracted domestic and foreign factors are a bit noisy, they depicted the economic crisis and recovery in 2007-2011 pretty well. As expected, domestic and foreign factors have similarities with common factor (domestic factor $G_{1, t}$ correlates with common factor by 0.88 , foreign factor $G_{2, t}$ correlates with common factor $F_{t}$ by 0.56 ). Even though correlation between $G_{1, t}$ and $G_{2, t}$ is positive 
(0.29) they have periods where they act opposite of each other, which is imminent since model specification allows them to correlate only through the common factor $F_{t}$.

\section{Combining the Indexes}

To determine the magnitude of the effect of domestic and foreign drivers to the Lithuanian economy, a simple linear model was built following macroeconomic forecasting example by Stock and Watson (2002) by regressing the growth of coincident index on both leading factor estimates. The 1-period ahead forecast was made:

$$
\Delta G D P_{t+1}=\alpha_{1} G_{1, t}+\alpha_{2} G_{2, t}+\varepsilon_{t+1}
$$

The estimates of parameters are in the table 1.

Table 1. Estimates of model parameters from equation (4)

\begin{tabular}{|c|c|c|c|c|}
\cline { 2 - 5 } \multicolumn{1}{c|}{} & Estimate & Std. Error & t value & p-value \\
\hline$\alpha_{1}$ & 0.297 & 0.113 & 2.639 & 0.010 \\
\hline$\alpha_{2}$ & 0.399 & 0.113 & 3.543 & 0.001 \\
\hline
\end{tabular}

Source: author's calculations.

Here $G_{1, t}$ was a the domestic leading factor, and $G_{2, t}$ was the foreign leading factor. It can be identified from table 1 that foreign factor has a larger load on the future state of economy which is not surprising since the focal economy is small and open.

\section{Dynamic Linear Model}

Equation (4) was evaluated under the assumption that the coefficients are fixed over time. Relaxing this assumption lets us build a dynamic linear state-space model to identify how the effects of domestic and foreign drivers of economy change over time and validate the hypothesis that the proportion of economic growth forecast explained by foreign indicators is increasing over time: 


$$
\begin{aligned}
& \Delta G D P_{t+1}=\alpha_{t} G_{1, t}+\left(1-\alpha_{t}\right) G_{2, t}+\varepsilon_{t+1}, \\
& \alpha_{t+1}=\psi \alpha_{t}+u_{t} .
\end{aligned}
$$

The parameters at $G_{1, t}$ and $G_{2, t}$ were constrained to sum to 1 in order to make this model identifiable. Under this specification our hypothetical statement means that the parameter $\alpha_{t}$ should be declining over time since $G_{1, t}$ is domestic factor. The parameters of this model were evaluated by maximum likelihood (assuming Gaussian innovations) and Kalman filtering. The prior value of $\alpha$ was set to match result from regression (4). The plot of dynamic coefficient $\alpha_{t}$ is in the Figure 2.

It can be identified from Graph 2 that the Russian crisis of 1998-1999 had a huge impact. Also, it shows that parameter $\alpha_{t}$ is decreasing, which means that the Lithuanian economy is more and more intertwined with other European economies. This result also validates our hypothesis about the increasing amount of explained forecast by foreign indicators. It leads to the conclusion that globalisation causes a quantifiable and increasing effect in focal economy.

Figure 2. Evaluated parameter series $\alpha_{t}$ - the parameter of domestic factor impact in future economy.

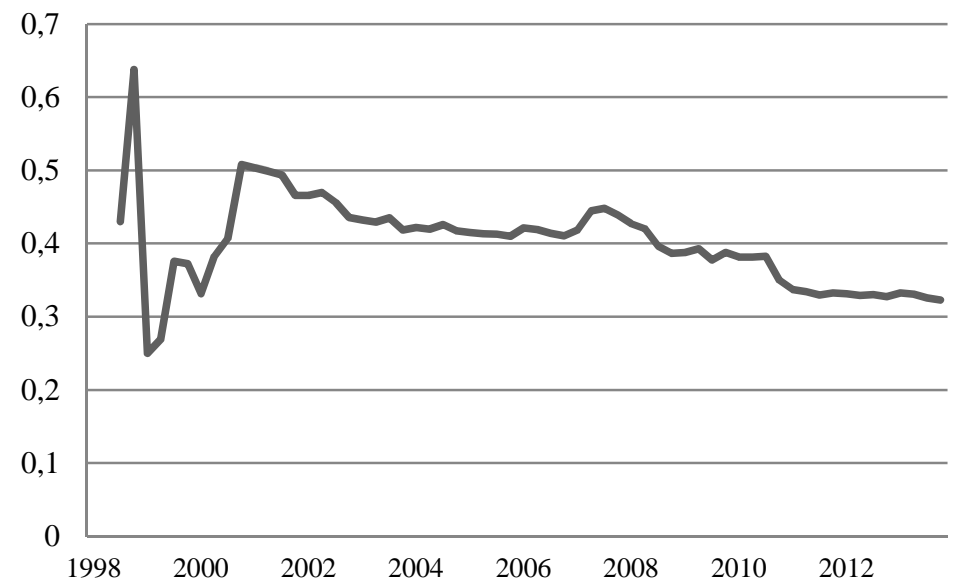

Source: author's calculations. 


\section{Conclusions}

In this paper a hypothesis was formed: due to globalisation the proportion of economic growth forecast explained by foreign indicators is increasing over time. In order to validate it, a hierarchical dynamic factor model was built. Using this structural approach, the domestic domestic and foreign drivers of economy were distinguished and their effects quantified. This measure offers a new view at globalisation since it is measured focusing on prediction rather than similarity and reveals how much focal country's economy is intertwined with global economy in terms of how sensitive it is to global shocks.

This new measure has a clear interpretation and withstands critique aimed at many other measures, such as obscurity of what exactly they measure, or lack of robustness in spite of their strong reliance on weighing and indicator selection. The factor model also deals with issue of data quality in sense of lacking measurement precision and infeasible incidators from different countries on the grounds that it extracts the signal from large data panels and discrepancies are recognized as noise.

The Lithuanian example showed that foreign series correspond to an amount which is increasing over time. This confirms not only that incorporating foreign data is useful, but also that in this framework the globalisation effect is visible and it can be monitored using dynamic linear models. These conclusions state that the hypothesis was validated and foreign information corresponds to an amount of forecast explained that is increasing over time.

\section{References}

Andersen, T.M., \& Herbertsson, T. T. (2003). Measuring Globalization, IZA Discussion paper series, No. 817.

Andersen, T.M., \& Herbertsson, T. T. (2005). Quantifying Globalization, Applied economics, 37(10). http://dx.doi.org/10.1080/00036840500118200.

Carter, C. K., \& Kohn, R. (1994). On Gibbs Sampling for State Space Models, Biometrica, 81(3). doi:10.1093/biomet/81.3.541.

Castelli, M. (2008). Measuring... What? Notes on some Globalization indices, Globalizations, 5(3). http://dx.doi.org/10.1080/14747730802252529.

Cubadda, G., Guardabascio, B., \& Hecq, A. (2012). A General to Specific Approach for Constructing Composite Business Cycle Indicators (Working Paper No. 224), CEIS.

Drechsel K., \& Scheufele, R. (2010). Should we trust in leading indicators? Evidence from the recent recession (Discussion paper No. 10), IWH. 
Dreher, A. (2006). Does globalization affect growth? Evidence from a new index of globalization. Applied Economics, 38(10). http://dx.doi.org/10.1080/000 36840500392078 .

Dreher, A., Gaston, N. \& Martens, P. (2008). Measuring Globalisation-Gauging Its Consequence. New York: Springer Science.

Fichtner, F., Rueffer, R., \& Schnatz, B. (2009). Leading indicators in a globalised world (Working paper No. 1125), European Central Bank.

Gaudreault, C. , Lamy, R. \& Liu, Y. (2003). New Coincident, Leading and Recession Indexes for the Canadian Economy: An Application of the Stock and Watson Methodology (Working paper No. 12), Department of Finance, Canada.

Heshmati, A. (2006). Measurement of a Multidimensional Index of Globalization. Global Economy Journal, 6(2). http://dx.doi.org/10.2202/1524-5861.1117.

Kearney, A. T. (2004). Globalisation Index. Foreign Policy.

Kim, S. \& Shin, E.-H. (2002). A Longitudinal Analysis of Globalization and Regionalization in International Trade: A Social Network Approach. Social Forces, 81(2). http://dx.doi.org/10.1353/sof.2003.0014.

Lockwood, B. (2004). How robust is the Foreign Policy/Kearney index of globalisation?. World Economy, 27(4). http://dx.doi.org/10.1111/j.0378-5920.2004. 00611.x.

Martens, P. and Zywietz, D. (2006), Rethinking globalization: a modified globalization index. Journal of International Development, 18(3). doi: $10.1002 /$ jid. 1223 .

Maslov, S. (2001). Measures of globalization based on cross-correlations of world financial indices. Physica A: Statistical Mechanics and its Applications, 301(14). http://dx.doi.org/10.1016/S0378-4371(01)00370-3

Moench, E., Ng, S., \& Potter, S. (2009). Dynamic Hierarchical Factor Models (Report No. 412), Federal Reserve Bank of New York.

Naghshpour S. \& Sergi, B. (2009). World trade indicators and a new approach to measure globalisation and countries' openness. International Journal of Trade and Global Markets. http://dx.doi.org/10.1504/IJTGM.2009.02303.

Petris, G. (2010). An R Package for Dynamic Linear Models. Journal of Statistical Software, 36(12).

Quinn, D. \& Toyoda A. (2008). Does capital account liberalization lead to growth? Review of Financial Studies, 21(3). http://dx.doi.org/10.1093/rfs/hhn034.

Reklaite, A. (2011). Coincident, Leading and Recession Indexes for the Lithuanian Economy. Baltic Journal of Economics, 11(1). http://dx.doi.org/10.1080/1406 099X.2011.10840492.

Stock, J. H., \& Watson, M. W. (2002). Macroeconomic forecasting Using Diffusion Indexes, Journal of Business and Economic Statistics, 20(2). http://dx.doi.org/10.1198/073500102317351921.

Villaverde, J., \& Maza, A. (2011). Globalisation, growth and convergence. World Economy, 34(6). http://dx.doi.org/10.1111/j.1467-9701.2011.01359.x. 